\title{
Artesanato e design: teoria e prática aplicadas ao desenvolvimento e comercialização de artefatos híbridos produzidos por projetos de extensão universitária
}

Crafts and design: theory and practice applied to the development and commercialization of hybrid artifacts produced by university extension projects.

CAMPESTRINI, Manoela Cristina; Acadêmica; Universidade da Região de Joinville- UNIVILLE manoelacampestrini@gmail.com

FONTANA, Daiane Laís; Acadêmica; Universidade da Região de Joinville- UNIVILLE daiane_fontana@hotmail.com

MORGENSTERN, Elenir; Professora Dra. em Design; Universidade da Região de JoinvilleUNIVILLE

elenir.m@gmail.com

ZAMBERLAN, Helena Morgenstern; Acadêmica; Universidade da Região de JoinvilleUNIVILLE

hzamberlan@gmail.com

\section{Resumo}

$\mathrm{O}$ artigo apresenta um recorte de pesquisa de Mestrado, ainda em andamento, que propõe, por meio da integração entre conhecimentos do design e saberes artesanais constituídos pela tradição cultural, a comercialização de artefatos produzidos por projeto social, de extensão universitária, que visa produção para geração de renda. Por intermédio de investigações bibliográficas e práticas, fundadas na antropologia social, o artigo destaca a relação dos termos 'design' e 'artesanato', presentes na produção do projeto AmaViva, tornando os artefatos híbridos. Por fim, evidencia a relação do artesanato e do design, na atualidade, e indaga acerca da relação recíproca, dos dois campos, na comercialização dos artefatos híbridos.

Palavras Chave: Artesanato; design; hibridismo.

\section{Abstract}

The article presents a Master's research study, still in progress, that proposes, through the integration between knowledge of the design and artisan knowledge constituted by the cultural tradition, the commercialization of artifacts produced by social project, of university extension, 
that aims at production for Increase in income. Through bibliographical and practical investigations based on social anthropology, the article highlights the relation of the terms 'design' and 'craftsmanship', present in the production of the AmaViva project, making the artifacts hybrid. Finally, it shows the relation of craftsmanship and design, in the present time, and inquires about the reciprocal relationship, of the two fields, in the commercialization of hybrid artifacts.

Keywords: Crafts; design; hybridism.

\section{Introdução}

Este artigo configura-se em recorte resultante de pesquisa de Mestrado, em andamento, que reflete acerca de teorias que embasam o artesanato e o design, vislumbrando aplicabilidade no projeto social, de extensão universitária, que objetiva produção com vistas a geração de trabalho e renda - Grupo AmaViva.

Apresentam-se, no desdobramento deste texto, definições dos termos 'design', 'artesanato' e 'hibridismo', bem como sua relação com o paradigma atual. Evidenciam-se características do grupo produtor - Projeto AmaViva - composto por mulheres artesãs de Joinville-SC, cadastradas pela Secretaria de Assistência Social de Joinville, que recebem apoio de professores e estudantes de design em ambiente acadêmico na UNIVILLE (Universidade da Região de Joinville).

Por fim, no intuito de prospectar as ações do grupo produtor, o artigo reflete acerca de um plano de negócio para a comercialização dos artefatos, possibilitando divulgação do projeto e, seguindo os objetivos da universidade, propiciando a indissociabilidade entre ensino, pesquisa e extensão.

\section{Definindo termos}

Nesta reflexão, faz-se necessário a definição de termos inerentes ao estudo aqui socializado: artesanato; design; e, hibridismo cultural.

$\mathrm{O}$ artesanato está presente em todos os períodos da história e, atualmente, está em evidência em várias áreas, com produtos elaborados e feitos à mão. Segundo o Sebrae (2004, p. 21) artesanato é "toda atividade produtiva que resulte em objetos e artefatos acabados, feitos manualmente ou com a utilização de meios tradicionais ou rudimentares, com habilidade, destreza, qualidade e criatividade". Já a Organização das Nações Unidas para a Educação, Ciência e Cultura (Unesco) apud Borges (2011, p. 21) explica:

Produtos artesanais são aqueles confeccionados por artesãos, seja totalmente a mão, com uso de ferramentas ou até mesmo por meios mecânicos, desde que a contribuição direta manual do artesão permaneça como o componente mais substancial do produto acabado. Essas peças são produzidas sem restrição em termos de quantidade e com uso de matérias-primas de recursos sustentáveis. A natureza especial dos produtos artesanais deriva de suas características distintas, que podem ser utilitárias, estéticas, artísticas, criativas, de caráter cultural e simbólicas e significativas do ponto de vista social. 
Toda atividade feita manualmente, sendo o manuseio o principal do produto, e com recursos sustentáveis torna-se um produto artesanal, mas para se tornar um artesão, de acordo com o entendimento de Sennet, é necessário 10 mil horas de experiência e quanto mais o artesão explorar técnicas e dedicar-se, mais será capaz de desfrutar o sentimento de competência. (SENNETT, 2015). Sentimento este, segundo o autor, vago na atualidade, onde a produção é prioritariamente tecnológica e em massa, deixando de lado o raciocínio, separando a mente das mãos (IDEM, 2015).

Em meados do século XVIII, segundo Kubrusly e Imbroisi (2011), as máquinas foram a invenção que transformou a produção e que fez com que acontecesse a Revolução Industrial e a produção manual foi substituída por equipamentos. Por conseguinte, o artesanato passou a ser uma forma alternativa de produção, e, como as grandes indústrias precisavam de mão de obra e contratavam muitos funcionários, as pessoas começaram a deixar de lado suas habilidades manuais, por uma questão de falta de tempo e também pela facilidade de comprar o produto já pronto. Durante esse período surgiram os cursos de desenho industrial, que tinham como objetivo criar para as grandes indústrias. Assim, o artesanato foi ficando cada vez mais isolado e definido em diversos momentos da história, conforme Sennett (2015), como uma atividade menosprezada.

$\mathrm{O}$ design tem papel relevante e grande relação com o artesanato, pode organizar informações e auxiliar no planejamento de artefatos. Lobach (2000, p. 16) argumenta que design é uma ideia, um projeto ou um plano para a solução de um problema determinado.

Para Kotler e Keller (2012, p. 354) o Design "é o conjunto de características que dizem respeito à aparência, à sensação e ao funcionamento do produto sob a perspectiva do consumidor. Oferece benefícios funcionais e estéticos, apelando tanto para o nosso lado racional quanto para o emocional", ou seja, nos dias de hoje, aproxima-se muito do artesanato.

A investigação, ora socializada, considera que algumas produções, na contemporaneidade, constituem-se híbridas, integrando design e artesanato. Canclini (2011) e Burke (2008) definem todas as culturas como de fronteira e ressaltam que a cultura se constitui do empréstimo de outra e assim se reformula constantemente. Sabendo da diversidade cultural existente, observa-se o hibridismo também na criação de artefatos. Mesmo que exista divergências de opiniões entre culturas, elas são apropriadas para a criatividade. Burke (2008) relata que a consideração pelo individual é primordial no encontro de diferenças culturais: é no individual que se encontra a força para a criatividade e o sentir-se agente na formulação de um produto.

\section{Design e artesanato na atualidade}

Desde o surgimento do design, na revolução industrial, o artesanato foi separado da área, sendo duas linhas definidas: a mecânica e a manual. Atualmente há uma retomada de conceitos, sites renomados da área de design de moda como WGSN e Usefashion, vem apresentando tendências de consumo e comportamento que referem o design e do artesanato.

Essa retomada é observada nos escritos de Canclini (2011, p. 22): "A modernização diminui o papel do culto e do popular tradicionais no conjunto do mercado simbólico, mas não os suprime. Redimensiona a arte e o folclore, o saber acadêmico e a cultura industrializada, sob condições relativamente semelhantes."

Observa-se, no Brasil, a riqueza de cultura, diversidade de técnicas e materiais disponíveis que dão oportunidade de desenvolvimento de artefatos unindo design e artesanato. Barros (2006, p. 28) afirma que "se a globalização é certa, cabe aos designers e 
artesãos participarem dos processos globalizantes buscando, através da comercialização dos produtos artesanais, a auto-sustentabilidade do artesanato brasileiro."

Há controvérsias acerca do trabalho entre os dois campos, mas Borges (2011, p.65) afirma que "muitos objetos artesanais são verdadeiras lições aos designers industriais, pelas engenhosas soluções de projeto, por usarem quase sempre matérias-primas não prejudiciais ao ambiente e por "falarem ao coração de seus usuários", na medida em que são objetos honestos, confiáveis e plenos de significado".

Krucken (2009, p. 43) escreve que "o designer busca por agregar valor a produtos, fortalecendo e estimulando a identidade local, é um forte impulsionador do investimento em design. Especialmente para economias emergentes, que anseiam posicionar-se de forma competitiva, o design representa um catalisador de inovação e da criação de uma imagem positiva ligada ao território, a seus produtos e serviços."

Tendo em vista a valorização da produção, faz-se necessário investigar questões pertinentes, como o 'gosto'. A instituição do gosto vem das relações sociais, as quais são caracterizadas por componentes simbólicos de local para local, grupo para grupo, comunidade para comunidade e assim por diante (BOURDIEU, 2007).

Segundo a visão do filósofo/sociologo Bourdieu (2007) a produção do artista e do designer deve ser analisada a partir de elementos extra-estéticos. Ou seja, o que compõe a análise de um produto, neste caso do design, são conhecimentos provenientes de uma análise crítica da produção, dos produtores, da economia e do mercado. Para o autor as produções do mercado são permeadas de ideologias de interesse dominante. Seguindo esse raciocínio, a capacidade produtiva dos agentes de design é suprimida quando o poder crítico do produtor é deixado de lado. Por outro lado, como identificar características do gosto de um produto que cative a atenção de quem o observa. Nesse sentido torna-se essencial contrapor o estabelecido e o que acontece nas relações cotidianas, permeadas de dizeres e fazeres do senso comum. É nestas relações que, segundo Bourdieu (2007), podem surgir novas produções e, sendo assim, com características que as fazem diferentes de um determinado padrão de produção.

As práticas produtivas de artesãos, bem como as técnicas e artefatos resultantes, são normalmente semelhantes. Entretanto, se houver colaboração do designer, no sentido de evidenciar as questões culturais relativas ao grupo produtor e ainda, na proposição de métodos que facilitem a produção e destaquem o valor técnico do artesanato, pode-se obter resultados que valorizem a produção e potencializem a comercialização. Muitas vezes as informações relativas a moda, estilos, acabamentos diversificados não chegam até os artesãos, mas o design pode levar essas propostas para enriquecer os produtos, no entanto devem sempre ser respeitadas e consideradas as culturas de cada região (KRUCKEN, 2009).

Com isso, o design tem de integrar saberes do artesanato e o artesanato integrar saberes do design. Faz-se relevante a colaboração, conforme Douek (2010) apud Kubrusly e Imbroisi (2011, p. 27): "É importante que se dê oportunidade de o artesanato chegar até o design e que o design venha se abastecer no artesanato".

Deve-se formar um diálogo entre esses dois campos, que foram separadas historicamente, como afirma Cipiniuk (2006): "Trata-se de integrar as classes sociais e as suas diferentes culturas dentro de um sistema que as separa".

Carvalho (2014) reforça a ideia de que o artesão produz pelo prazer, pela emoção, se for privado disso, o resultado não será o mesmo. Portanto, é preciso observar e considerar as características desse trabalho e enriquecer os artefatos desenvolvidos sem modificar a essência do artesão. Torna-se relevante inserir um projeto de design como este aqui proposto em um 


\section{GAMPI}

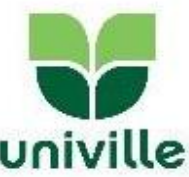

grupo de mulheres artesãs que buscam gerar renda às suas comunidades, a fim de que tenham um produto ainda mais rico.

\section{Projeto de extensão que visa geração de renda}

Atualmente, percebe-se o grande número de grupos de artesãos no Brasil. Carvalho (2014) argumenta que a maioria deles são formados por mulheres, que dominam facilmente esse tipo de atividade. Os artesãos, em sua grande parte, desenvolvem trabalhos relacionados a sua vida cotidiana e cultura. Um exemplo de grupo de artesãs é o AmaViva que recebe o apoio de estudantes e professores da área do design, fortalecendo os processos para a produção de artefatos.

A capacitação para o empreendedorismo está no escopo do projeto de extensão 'Amadurecer e viver: associando saberes na Univille [AmaViva]' da Universidade da Região de Joinville - UNIVILLE. Este projeto congrega artesãs, remanescentes de projetos que capacitam para geração de renda, com vistas à produção e comercialização associada de artefatos. O público alvo é, então, constituído por artesãs provenientes do projeto "Geração de renda: Mulher Sempre-viva (SEMPRE-VIVA)" que sentem a necessidade de dar continuidade às suas atividades em grupo. (www.sempreflor.com, 2017)

São aplicadas neste projeto demais capacitações abrangendo temas como criatividade, marketing, identidade visual, técnicas artesanais, tecelagem, saberes relacionados à moda, desenvolvimento de mobiliário e marcenaria, fazendo com que seus conhecimentos se ampliem e formem profissionais para a própria geração de renda.A produção de artefatos é feita conforme demandas e os materiais utilizados são provenientes de doações ou parcerias estabelecidas com empresas da região (IDEM, 2017).

Figura 01: Grupo AmaViva 2015

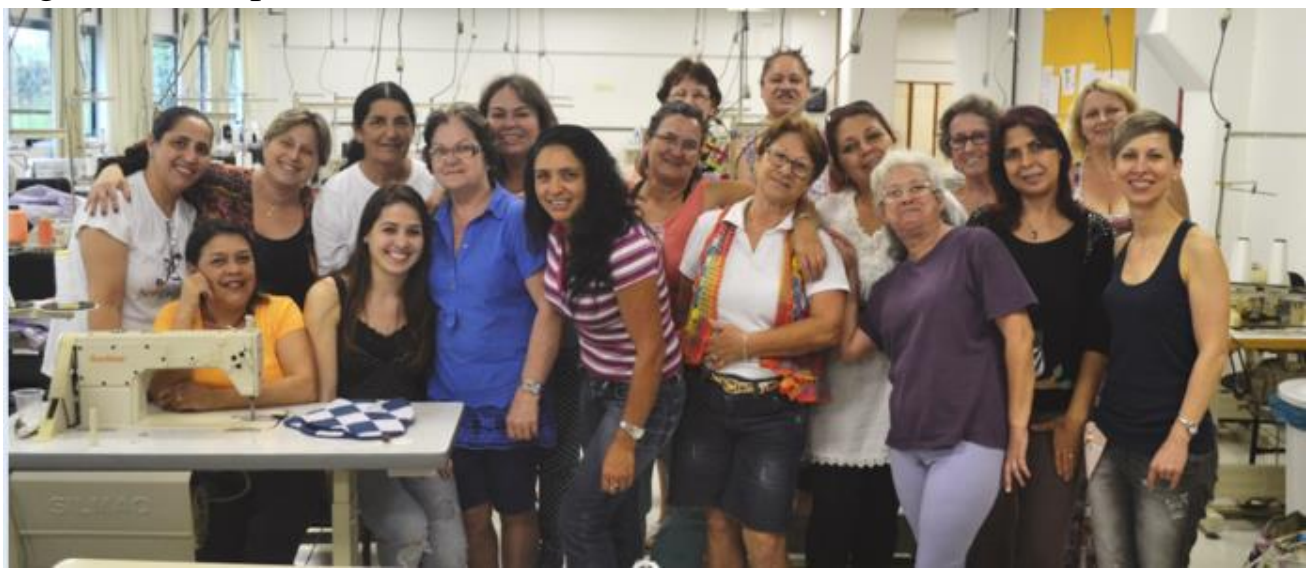

Fonte: Primária (2015)

Artefatos produzidos por este projeto recebem influências das artesãs participantes e também do design, unindo essas duas áreas observa-se a criação de artefatos híbridos, que a partir do diálogo das partes formam um artefato enriquecido de conhecimentos diferentes e valor agregado.

Observando esses artefatos, busca-se fabricar peças para a comercialização, criação formas de metodologia de trabalho, pesquisas de mercado e ainda a projeção de coleções 
atreladas às metodologias do design.

\section{Comercialização de artefatos híbridos}

Conforme Salcedo (2014), vivemos em um novo paradigma, com grande consumo e produção, devastação ambiental e esgotamento de recursos, porém este ritmo acelerado não poderá ser levado a diante, o planeta está desequilibrado. Precisamos produzir produtos que sejam agradáveis ao meio ambiente, considerando desde a criação até seu descarte.

A indústria da moda, conforme Berlim (2012) está entre as que mais geram empregos mundialmente, sendo esta a que gera mais resíduos não só na etapa de fabricação, mas também em forma de descarte, o pós uso.

Os artefatos, cuja produção é descrita nesta pesquisa, atendem e acompanham a realidade atual, por meio de aplicações materiais que atendem aos princípios da sustentabilidade e consideram questões sociais, com a busca de geração de renda para o grupo produtor. Cabral (2007, p.71) destaca a relação recíproca que pode desdobrar-se entre artesanato e design: "Design é aquele agente que surgiu nas industrializações, atuando na criação, na adaptação funcional, na configuração formal e na apresentação do produto industrial ao mercado, agora aparece como o profissional contratado também para qualificar o artesanato para o mercado".

Observando a atualidade e os artefatos produzidos, conforme relatado nesta pesquisa, confirma-se em Canclini (2011) e Burke (2008) que a união entre artesanato e design podem resultam em um artefato culturalmente híbrido. Burke (2008) relata que a consideração pelo individual é primordial no encontro de diferenças culturais: é no individual que se encontra a força para a criatividade e o sentir-se agente na formulação de um produto.

Desse modo, torna-se relevante um planejamento para a venda dos produtos. Para isto, observa-se a necessidade utilizar ferramentas para a organização da comercialização. Segundo Dornelas (2003), o Plano de Negócios, é um documento que auxilia no planejamento, estruturando as principais ideias e objetivos, diminuindo riscos durante o processo. A ferramenta auxiliará na análise de mercado, concorrentes, gastos e outras questões pertinentes para a formação de um negócio (DORNELAS, 2003).

O planejamento com base na área da administração juntamente com o Design fortalece e posiciona o produto no mercado. Observa-se em Aguiar (2014) que o Design é uma área que tem uma visão holística do conhecimento e possui foco na resolução de necessidades e desejos das pessoas.

Desse modo, a pesquisa ora relatada investe no planejamento da venda de produtos com referências na área da administração em moda, analisando consumidores e meios possíveis de venda atrelando-se também com o design para que os artefatos com refugos produzidos por projeto gerador de renda sejam reconhecidos pela comunidade e pelo público alvo e comercializado. O plano de negócio evoluirá a partir da contribuição de duas pesquisas de PIBIC de estudantes da graduação em Design vinculadas ao Mestrado.

Uma das pesquisas desenvolvida pela estudante está relacionada à pesquisa teórica, apoiando principalmente a verificação dos limites e hibridismos entre as atuais práticas do design de moda, a arte, o artesanato e a tecnologia, por meio de levantamento de questões acerca das fronteiras do design na contemporaneidade; a referida pesquisa de PIBIC também investe na verificação das produções atuais do design de moda estabelecendo relações com a cultura e sociedade. 
A segunda pesquisa de PIBIC desenvolvida pela estudan, investe no desenvolvimento da identidade visual para os artefatos híbridos, produzidos por projeto de extensão da UNIVILLE; seu desdobramento envolve criação da marca, nome e símbolo ou logotipo, projeção de materiais expositivos que divulguem os artefatos produzidos pelos projetos de extensão e embalagem e instrumentos de divulgação online e impresso como: folders, cartões e banners.

\section{Considerações Finais}

$\mathrm{O}$ artigo apresentou um recorte de pesquisa de Mestrado, ainda em andamento, que propõe, por meio da integração entre conhecimentos do design e saberes artesanais constituídos pela tradição cultural, a comercialização de artefatos produzidos por projeto social, de extensão universitária, que visa produção para ampliação de renda.

Em seu desdobramento o artigo destacou definições teóricas de termos e suas relações, resultantes de pesquisa ainda em andamento. Os termos apresentados, artesanato, design e hibridismo, foram definidos e situados historicamente observando o encontro entre os campos.

Destacou-se características do paradigma atual e a influência do artesanato e do design na atualidade, observando que é possível este cruzamento que valoriza a produção e promove questões sociais e culturais.

O grupo produtor apresentado evidenciou a presença de grupos de mulheres artesãs nos dias de hoje e a diversidade de culturas que congregam conhecimentos que influenciam na produção dos artefatos. Com produtos que integram o artesanato e o design é possível a comercialização, assim o artigo evidenciou a relevância de desenvolver-se um plano de negócio que propicie a organização de ideias e objetivos de vendas, com vistas a geração de renda e divulgação do projeto junto à comunidade.

Conclui-se que a interseção entre artesanato e design é possível e enriquece não apenas os artefatos comercializados, mas também contribuiu em questões sociais presentes na atualidade.

\section{Referências}

AGUIAR, Victor R. L. Design de serviços no atendimento ao cliente. Joinville, 2014. No prelo.

BARROS, Luiz Antonio dos Santos. Design e artesanato: As trocas possíveis. 2006. Dissertação mestrado em design De partamento de artes e design, pontifícia Universidade católica do Rio de Janeiro, Rio de Janeiro, 2006.

BERLIM, Lilyan. Moda e sustentabilidade: uma reflexão necessária. São Paulo: Estação das Letras e Cores, 2012.

BORGES, Adelia. Design + Artesanato: o caminho brasileiro. São Paulo: Editora Terceiro Nome, 2011.

BOURDIEU, Pierre. A economia das trocas simbólicas. São Paulo: Perspectiva, 2007. 
BURKE, Peter. Hibridismo cultural. São Leopoldo: Ed. UNISINOS, 2003.

BRASIL. Guia de Ações para a Geração de Trabalho e Renda. Ministério do Desenvolvimento Social e Combate à Fome. Brasília, DF, 2009.

CABRAL, Fabrícia Guimarães Sobral. Saberes sobrepostos: Design e artesanato na produção de objetos culturais. 2007. Dissertação mestrado em design De partamento de artes e design, pontifícia Universidade católica do Rio de Janeiro, Rio de Janeiiro, 2007.

CANCLINI, Néstor García. Culturas híbridas: estratégias para entrar e sair da modernidade. 4. ed. São Paulo: EDUSP, 2011.

CARVALHO, Monica Almeida de. Artesanato sustentável: natureza, design e arte. Rio de Janeiro: SENAC Nacional, 2014.

DORNELAS, José Carlos de Assis. Empreendedorismo corporativo. Rio de Janeiro: Elsevier, 2003. 300 p.

KEBRUSSLY, Maria Emília; IMBROISI, Renato. Desenho de fibra: artesanato têxtil no Brasil. Rio de Janeiro: Senac Nacional, 2011.

KOTLER, Philip e KELLER, Kevin L. Administração de Marketing. São Paulo: Pearson Education do Brasil, 2012.

KRUCHEN, Lia. Design e território: valorização de identidades e produtos locais. São Paulo: Studio Nobel, 2009.

LOBACH, Bernd. Design industrial: bases para a configuração dos produtos industriais. Editora Edgard Blucher, 2000.

LORENZI, Rita. Design de moda e artesanato: uma relação social recíproca. Dissertação de mestrado. Universidade da Região de Joinville, Joinville, 2015.

SEBRAE. Programa Sebrae de artesanato: termo de referência. São Paulo, 2004. SEMPREFLOR http://www.sempreflor.com.br/ acesso: 21/05/2017

SENNETT, Richard. O Artífice. $5^{\text {a }}$ edição, Rio de Janeiro editora: Record, 2015 tradução de Clóvis Marques.

SALCEDO, Elena. Moda ética para um futuro sustentável. Tradução: Denis Fracalossi. Barcelona: Editora Gustavo Gili, 2014. 